\begin{tabular}{|l|l|l|}
\hline Revista & & $\begin{array}{l}\text { Revista Latina de Sociología (RELASO) } \\
\text { Vol. } 5 \text { (2015) pp. 33-44. ISSN-e 2253-6469 } \\
\text { DOI: http://dx.doi.org/10.17979/relaso.2015.5.1.1516 } \\
\text { Cotina } \mathrm{UDC} / \mathrm{Uminho}\end{array}$ \\
de Sociologia & $\quad$ & \\
\hline
\end{tabular}

\title{
La sociología como mirada estética de las formas de vida: el arte según Georg Simmel
}

Sociology as aesthetic outlook of the forms of life: art according to Georg Simmel

Eugenia Fraga

Consejo Nacional de Investigaciones Científicas y Técnicas (CONICET, Argentina)

E-mail: euge.fraga@hotmail.com

Recibido/Received: 16/06/2015

Aceptado/Accepted: 19/08/2015

\section{RESUMEN}

En el presente trabajo indagaremos en la perspectiva de Georg Simmel, la cual nos resulta de especial interés puesto que se erige como una sociologia inescindible de la estética. Como veremos, la mirada sociológica es siempre también una mirada artística sobre el mundo. Las implicancias de esta afirmación para el quehacer teórico dentro de la disciplina sociológica son radicales, puesto que si la sociología tiene algo de "arte", entonces el sociólogo es una especie de "artista", y el mundo social mismo permite ser concebido como "obra de arte". La sociología es para este autor una mirada singular, que como toda mirada humana guarda en su seno algo de artística, por su conexión íntima con la experiencia totalizante de la unidad estética originaria, así como con la apreciación de la heterogeneidad de sus manifestaciones. La especificidad de la disciplina sociológica es el estudio de las formas, con independencia de los contenidos, de la vida social; las formas de vida social, en tanto estilizaciones de dicha vida en su eterno despliegue, son aprehensibles de manera estética; en tanto expresiones de la cultura humana, son aprehensibles de manera artística; y por ello, en definitiva, la captación de las culturas y los estilos de las formas de vida social deviene posible a través de la sociología como mirada artística y estetizante de las mismas.

Palabras clave: Simmel; arte; obra de arte; artista; sociología; estética

\section{ABSTRACT}

In the present paper we will analyse the perspective of Georg Simmel, which is of special interest for us since it postulates a sociology that is inseparable from aesthetics. As we will see, the sociological outlook is always also an artistic outlook on the world. The consequences of this postulation for theoretical work inside the sociological discipline are radical, for if sociology is a kind of "art", then the sociologist is a kind of "artist", and the social world itself can be conceived as a "work of art". Sociology is, for this author, a particular outlook that, like every other human outlook, holds an artistic element, given its intimate connection with the

Sugerencia de cita/ Suggested citation: Fraga, Eugenia (2015). La sociología como mirada estética de las formas de vida: el arte según Georg Simmel. Revista Latina de Sociología, 5, 33-44. 
totalizing experience of the originary aesthetic unity, and with the appretiation of the heterogeneity of its manifestations. The specificity of the sociological discipline is the study of the forms, with independence of the contents, of social life; the forms of social life, in so far as they are stylizations of such life in its unfolding, are apprehensible in an aesthetic way; in so far as they are expressions of human culture, they are apprehensible in an artistic way; and this is why, in conlusion, the possibility of capturing the cultures and the styles of the forms of social life is given by sociology as an aesthetic and artistic outlook on them.

Keywords: Simmel; art; work of art; artist; sociology; aesthetics

\section{Introducción}

En el presente trabajo indagaremos en la perspectiva de Georg Simmel. Su perspectiva nos resulta de especial interés puesto que se erige como una sociología inescindible tanto de la filosofia en general como de la estética en particular. Así, como veremos, la mirada sociológica es siempre también una mirada artística sobre el mundo (De La Fuente, 2008). Las implicancias de esta afirmación para el quehacer teórico dentro de la disciplina sociológica son radicales, puesto que si la sociología tiene algo de "arte", entonces el sociólogo es una especie de "artista", y el mundo social mismo permite ser concebido como "obra de arte". Organizaremos el trabajo en dos ejes. Primero analizaremos la relación entre el arte y el resto de los fenómenos sociales, especialmente los que interesaban a Simmel, como la lucha, la sociabilidad, la coquetería, la religión, la aventura, la ciencia, el juego, el secreto y el paisaje. Aquí veremos cómo la analogía artística sirve para comprender más profundamente estas formas de vida. En segundo lugar, sistematizaremos aquello que el autor postuló respecto del arte como fenómeno con entidad propia, para mejor comprender cómo deberemos entender a la sociología. Aquí lo artístico -y por ende, también lo sociológico- será concebido como fenómeno a la vez cultural y estilístico (Frisby, 1992). Finalmente, y a modo de conclusión, ataremos los hilos de la argumentación precedente mostrando de qué modo la particular forma simmeliana de concebir al arte deriva en un modo singular de entender a la sociología.
2. . Relación entre el arte y otras formas de vida

En Cuestiones fundamentales de sociologia, Simmel postula que la unidad de análisis de la sociología, a diferencia de lo que sugieren muchos de sus contemporáneos, no es una entidad llamada "la sociedad", sino el conjunto de las diversas "formas de socialización". De estas formas, la más abstracta y general, la más pura por la irrelevancia casi total de su contenido particular, es la sociabilidad. Es necesario tomar aquí la noción de forma en toda su profundidad: la sociabilidad es su propia formalidad, es un fenómeno social morfológico. Es este rasgo singular el que lleva al autor a comparar la sociabilidad con el arte:

"El estar juntos y la interacción en los que se manifiestan todas las obligaciones y toda la gravedad de la vida, se gozan aquí en un juego en cierto modo artístico, en aquella forma al mismo tiempo sublimada $\mathrm{y}$ diluida en la que las fuerzas de la realidad dotadas de contenido sólo resuenan como de lejos, desvaneciéndose su peso $\mathrm{y}$ convirtiéndose en un atractivo" (Simmel, 2002: 101).

La sociabilidad, o "el arte del estar juntos", depende justamente del hecho de la socialización, del hecho mismo de constitución del lazo, y resulta en ese sentido independiente de los sujetos que en ella participan, de los tiempos y espacios en los que se despliega, y de las motivaciones que la movilizan. Algo similar sucede con el fenómeno artístico: su impulso puede provenir de los contenidos y materialidades de la vida, pero sólo puede realizarse cuando extrae de dichos contenidos y 
materialidades unas ciertas formas $y$ figuras, abstraídas respecto de ellos. Justamente, el arte implica una estilización respecto del mundo, generalmente mediante una simetrización o equilibramiento del mundo, inherentemente caótico.

Ahora bien, el hecho de que el arte se abstraiga del contenido de la realidad, no implica en modo alguno una desviación de la misma, o una representación engañosa. Inauténtica, paradójicamente, sólo es aquella obra de arte que se limita a imitar el mundo, sin mediación de la subjetividad. Este parámetro de medición de la verdad o falsedad del arte es el mismo que Simmel aplica al análisis de la sociabilidad: el "arte de conversar" no es menos sincero por focalizarse en las puras formas de su devenir, en su atractivo y poder de seducción del otro, sino que ésta es el soporte mismo del intercambio vivo. Efectivamente, por más estilizada que resulte la relación social, o por más fantasiosa que resulte una obra de arte, ambas se nutren de la realidad de manera profunda. Situarse "por encima de la vida", al fin y al cabo, no equivale a "flotar en la nada", sino a "recostarse" sobre esa vida, que hace las veces de cimiento, de raíz, de motor, en nuestro caso, del arte. El arte, entonces, emerge de este acercarse y alejarse, simultáneamente, respecto de la realidad. Y ese vaivén es apreciable sobretodo por las figuras que dibuja:

"La configuración de realidades perceptibles e imperceptibles según formas espaciales cerradas, ritmo y sonido, significado y organización, surgió sin duda originariamente de las exigencias de nuestra práctica. Pero cuando estas formas se convierten en fines en sí mismos y ejercen su efecto por su propia fuerza y su propia ley, selectivas y creativas desde ellas mismas y no en función de su entrelazamiento con la vida, entonces ha surgido el arte, por completo separado de la vida y extrayendo de ésta sólo lo que le sirve y que por medio de él se genera en cierto modo por segunda vez" (Simmel, 2002:

80).

Las formas son la modalidad de objetivación inherente al despliegue de la vida práctica, material, pero ellas pueden autonomizarse de tal modo que se convierten en una de las metas de la vida misma. Este rasgo "utilitario" del arte, que entonces hace uso de los elementos del mundo que le sirven, desechando los que no requiere, permite establecer una nueva analogía, esta vez entre el arte y el juego. El juego, otra de las formas de socialización analizadas por Simmel, se asemeja al arte en el hecho de que implica una cierta deformación de la vida, una cierta reproducción borroneada o incluso invertida de ella. Sin embargo, aún la inversión total de la vida al interior del formalismo del juego precisa alimentarse de esa vida, de la cual toma su sentido, y sin la cual quedaría vacío. El arte es un juego de formas; el arte es también una forma del juego.

$\mathrm{El}$ modo en que las formas se combinan en el arte, el modo en que entran en relación las partes del fenómeno artístico total, no es aleatorio sino que responde a la legalidad propia de los objetos y elementos representados, y guarda una intima atadura con ellos. El mundo presenta una integridad, una plenitud, que, aunque dificil de formular en forma inmediata, aparece legitimamente representada en la obra de arte como entidad totalizante. La obra de arte sería entonces un contenedor de la vida, y éste, paradójicamente, es su elemento liberador. En la esfera artística, uno se encuentra libre respecto de la inmediatez de la vida, pero al mismo tiempo, la posee de un modo más fuerte, más íntimo, más conciente que nunca. Este rasgo singular del arte sólo es compartido con los reinos de la religión y de la ciencia, que se abstraen del mundo pero lo representan y lo contienen de manera igualmente acabada. Por otro lado, estas asociaciones entre superficie y profundidad, entre forma $\mathrm{y}$ contenido, seguirán apareciendo todo a lo largo de nuestro análisis del concepto simmeliano de arte (Fedorovsky, 2011).

Simmel, al concebir a la lucha como una forma de relación social, con igual derecho 
a la indagación sociológica que las formas armoniosas del lazo, dedica en Sociología. Estudios sobre las formas de socialización especial atención al fenómeno de la competencia. Así, postula la existencia de ciertas formas de la competencia establecidas en torno a lo que denomina "valores espirituales". Uno de los valores espirituales, por supuesto, es el arte. Para el autor, los artistas se enfrentan entre sí en la búsqueda de los máximos rendimientos culturales:

\begin{abstract}
"En las competencias artísticas [...] los impulsos subjetivos y antagónicos nos conducen a la realización de valores objetivos, y la victoria no es propiamente el resultado de una lucha, sino de realizaciones de valor que están más allá de la lucha"
\end{abstract} (Simmel, 1939a: 281).

Como podemos ver, independientemente de lo que lleva a los individuos dedicados a la producción artística a producir obras de arte y a competir en el reconocimiento de sus producciones, lo que importa, en términos sociológicos, es el producto artístico en sí mismo. Si bien el arte surge como motivación subjetiva, su realización implica un valor objetivo. En otras palabras, más allá de cuál artista o cuál obra de arte sea considerada superior, la verdadera ganadora en estas competencias es siempre el arte. La lucha aquí es en realidad un mero medio para un fin que la trasciende: el acrecentamiento de los bienes materiales y espirituales del ámbito cultural. La competencia, de hecho, no es más que un incentivo individual para el beneficio colectivo. Las tensiones aquí planteadas entre lo subjetivo y lo objetivo, entre el medio y el fin, entre lo individual y lo colectivo, también atravesarán, junto a otras que irán emergiendo, la totalidad de la problemática del arte (Quiña, 2013).

Simmel prosigue sus analogias en Sobre la aventura. Ensayos filosóficos, esta vez estableciendo un contrapunto entre el arte y la coquetería. Como el arte, la coquetería se funda en un aligeramiento de la realidad, en la "suspensión en el aire" de los contenidos firmes de la vida, en un fenómeno que estiliza e idealiza el mundo, poniendo toda la atención en el juego de sus formas. De aquí que se hable muchas veces de las "artes de la coquetería", del juego de la seducción, del poder abstracto de la atracción. La coquetería, del mismo modo que el arte, invierte la mediación, en este caso de la fantasía erótica, en un puro fin:

"Kant ha dicho de la esencia del arte: 'finalidad privada de fin'. La obra de arte carece, ciertamente, de 'fin' -y, sin embargo, sus diversas partes aparecen ensambladas de una manera tan llena de sentido, cada una necesaria en su lugar, como si concurriesen a la consecución de un fin completamente prefigurado-" (Simmel, 1988a: 157).

$\mathrm{El}$ arte carece de fin porque no posee una meta que lo trascienda; pero al mismo tiempo, es un fin en sí mismo, pues obtiene de sí mismo su derecho a existir y su sentido. Asimismo, el arte, como la coqueteria, implican fundamentalmente un juego de combinaciones entre partes, de encastres de elementos heterogéneos, que sin embargo conducen a la creación de una totalidad, sea en la forma de la obra de arte, sea en la forma de un encuentro erótico.

Por otro lado, tanto los artistas como los participantes de un coqueteo juegan con la apariencia de la realidad. En otras palabras, se abstraen de la continuidad de la existencia, de la cual sin embargo se alimentan. Este juego de apariencias supone una relación singular entre el arte o la coqueteria- y su objeto: ambos se conducen con indiferencia respecto de éste último. En efecto, resulta sociológicamente irrelevante, en última instancia, cuál es el tema de una obra de arte, o cuál es el objeto de deseo de un individuo. Lo verdaderamente importante es la forma que dibujan esas relaciones al desplegarse. Los elementos que el arte toma prestados de la serie de la vida pueden ser morales o inmorales, sagrados o profanos, naturales o artificiales, etcétera, pero ello no afecta su sentido artístico. Al ingresar a la esfera del arte, pierden sus atributos anteriores y pasan a ser valorados en términos estrictamente estéticos (Rammstedt, 1991). 
Reaparece aquí la cuestión del "utilitarismo" del arte: el arte, con el artista como intermediario, puede servirse, legítimamente, de cualquier objeto o sujeto del mundo, todas las realidades sirven al arte, porque ella sólo toma de la realidad sus formas. De aquí la tensión antes enunciada entre la posesión y la no posesión de la vida:

"Las artes son lo que los
franciscanos decian de sí
mismos: omnia habentes, nihil
possidentes [tengo todo, sin
poseer nada]" (Simmel, 1988a:
161, aclaración entre corchetes
propia).

El arte se ubica así por encima del poseer pero también del no poseer: el arte posee todas las cosas, porque se encuentran disponibles para su utilización estética en todo momento, y simultáneamente, no posee ninguna, porque jamás las aprehende en su realidad práctica. Esta misma lógica es la de la coquetería: el juego erótico dura tanto como la indefinición de la posesión. En el momento en que se determina si se va a poseer o no al otro sujeto, termina la coquetería, y en todo caso comienza la relación sexual o amorosa propiamente dicha. En otras palabras, se sale de la esfera del juego y se entra en la de la realidad, se sale de la idealidad y se pasa a la materialidad. Podemos entonces establecer una triangulación de asociaciones. Tanto el arte como la coquetería son formas del juego, y tanto el juego como la coquetería son estilizaciones. Pero el hecho de que el arte pueda ser pensado como juego tiene que ver, paradójicamente, con que se toma profundamente en serio la vida, de modo incluso más penetrante que como la vida práctica se toma a sí misma.

El arte se asemeja entonces, para Simmel, a otra de las formas de socialización: la aventura. La aventura, explica el autor en Cultura femenina $y$ otros ensayos, es un paréntesis en la vida cotidiana, es un recorte, una pausa, un fragmento, salido del mundo real y abstraído de él idealmente en el caso del arte, prácticamente en el caso de la aventura-. Sin embargo, en ese fragmento, en ese recorte, se recrea el sentido total de la vida, se reproduce en toda su profundidad la existencia, se experimenta en forma singular esa realidad. De hecho, la vivencia del acontecimiento artístico o aventurero es más cabal que la vivencia cotidiana del mundo práctico. El pedazo de vida que se pone entre paréntesis, queda así resaltado respecto a la serie siempre igual a sí misma de las exigencias cotidianas, rodeándose de un aura especial, de un sentimiento extraordinario. En palabras del autor:

"La esencia de la obra artística
consiste en destacar, en
recortar un trozo en la serie
infinitamente continua de lo
visto o de lo vivido, desligándolo
de toda clase de conexiones y
dándole una forma suficiente,
[...] como si en cada una de ellas
se concentrara y agotara toda la
vida" (Simmel, 1934: 125).

$\mathrm{El}$ arte, como la experiencia aventurera, es entonces un parte que condensa al todo. En un bocado de vida se puede saborear la vida entera. Algo similar, aunque no exactamente igual, sucede con el fenómeno del secreto. El secreto, para Simmel, obtiene su "magia", su encanto, del hecho de que da, a quienes no se encuentran en posesión del secreto, la idea de que en él se concentra alguna verdad fundamental. El halo misterioso que recubre tanto al arte como al secreto es parte de la explicación de su efecto en los individuos. Y aquí se ve también cómo el secreto parecería ser el fragmento de la vida de un sujeto, que sin embargo, a los ojos de los demás, se presenta como contenedor de su vida entera. El secreto, como el arte, parecería ser la forma de expresión fragmentaria de la propia individualidad:

"Para el artista la forma de su arte es la única posibilidad que se le ofrece para manifestar toda su interioridad" (Simmel, 1939b: 346).

La obra de arte es un objeto limitado, incluso pequeño en relación a la totalidad de objetos con los que un sujeto entra en relación a lo largo de su existencia. Y sin embargo, dentro de sus límites se expresa de manera rotunda lo más profundo de esa inabarcabilidad. Tan central es la 
personalidad puesta en la obra, que cuando ella es plasmada de modo transparente, pierde toda relevancia la cuestión del estilo de la obra. Cuanta más "vida subjetiva", cuanta más singularidad y particularidades personales posea una obra de arte, menos interesa su clasificación estética general. Esto, a diferencia de lo que sucede en las "artes industriales", cuyos productos, en tanto meramente utilitarios, se basan en la abstracción de lo singular y en la búsqueda de lo masivo y plural. Mientras que en las "bellas artes" el foco está puesto en lo único, en la producción industrial el foco está puesto en lo típico. Los objetos seriados no intentan reproducir el alma humana, sino facilitar su vida práctica. La relevancia de sus obras no es individual, sino eminentemente histórica y colectiva. Una obra industrial, entonces, se inserta en el sistema de vida práctico de un grupo; una obra de arte, en cambio, se inserta en el sistema de vida psíquico de un sujeto. La producción industrial se encaja en la vida real, pero la producción artística se abstrae de ella (Castillo Castillo, 1998).

El arte, explica Simmel en Roma, Florencia, Venecia, se sirve de diversos elementos preexistentes, uniéndolos con el objetivo de generar algún tipo de belleza. Independientemente del tipo de belleza que se busque generar, el elemento que permite considerarla tal es que ella siempre conforma un sentimiento de unidad, de totalidad. Este mismo rasgo, precisamente, es el que al autor lo habilita a asemejar el arte al paisaje como fenómeno estético. Ya se trate de un paisaje puramente natural, de un paisaje puramente artificial, o de un paisaje mixturado, lo que genera en el espectador la sensación de belleza es la de su unidad, la de su propio cierre simbólico.

"Si el intento de crear una
relación de pertenencia unitaria
en el alma a partir de la
diversidad original de las cosas
y las imágenes es uno de los
rasgos del carácter humano,
posiblemente incluso el más
hondo, entonces puede
pensarse que ras
manifestaciones del arte no
sean más que una especial
manera y forma en que lo

conseguimos, que el arte sea sólo una de las vías de diversidad externa -o incluso interna- que conducen a la unidad interna, de modo que la importancia de una obra de arte crecería en la medida en que la diversidad de sus condiciones, de su material y de la problemática tratada sea mayor, y en la medida en que la unidad en la que sabe encerrarlo todo sea más estrecha, fuerte $\mathrm{y}$ unitaria. La tensión entre la diversidad y la unidad de las cosas que confieren a la obra de arte evocaciones y sensaciones sería la medida de su valor estético" (Simmel, 2007: 27-28).

Analicemos en detalle esta extensa cita del autor. El trayecto de todo fenómeno artístico pareciera ser aquel que va de lo heterogéneo a lo homogéneo, aquel que se origina en la diversidad y finaliza en la unidad. Esto tiene que ver, según la perspectiva de Simmel, con que el alma humana tiende a buscar o a crear objetos que le permitan verse contenida en ellos de manera acabada, completa. De este modo, el arte sería uno de los medios para alcanzar esta meta esencial al hombre. De hecho, más rica resulta una obra de arte es decir, logra con mayor intensidad agradar al alma-, cuanta más heterogeneidad logre condensar en su producto final. Y este juego entre lo diverso y lo unitario al interior de una misma obra de arte es lo que le otorga a la misma su carácter siempre abierto, paradójicamente. Porque dada su heterogeneidad fundacional, el objeto terminado se encuentra sujeto a una heterogeneidad de interpretaciones, de sensaciones.

Como se mencionó con anterioridad, otro de los medios para cumplir con esta necesidad del alma humana es el paisaje. Cuando la multiplicidad de formas en que se presenta la naturaleza, es combinada de tal modo con la multiplicidad de las creaciones arquitectónicas humanas, de tal modo que juntas logran generar un paisaje bello, entonces se produce un efecto similar al de la obra de arte. Esta combinación de naturaleza y espíritu, este darle forma 
cultural a los elementos naturales del mundo, es el rasgo que comparten las bellas artes y el arte paisajístico. Tanto en el paisaje como en la obra de arte propiamente dicha, el espíritu de la naturaleza emerge tomando una forma humana. Sin embargo, el dualismo entre el espíritu y la naturaleza nunca se salda, nunca se cierra sino que permanece latente aún cuando se presente en forma armónica. En palabras del autor:

"Gracias a esta pérdida de tensión entre naturaleza y espíritu se genera el ambiente estético, la sensación de encontrarse frente a una obra de arte" (Simmel, 2007: 38).

$\mathrm{Si}$ bien es de resaltar la importancia que adquieren los detalles, tanto en la obra de arte como en el paisaje, su relevancia viene dada por el hecho mismo de estar incluidos en el fenómeno estético total. Los detalles resultan importantes en tanto forman sistema con el resto de los elementos de la obra, así como con la obra misma como producto cerrado. Gracias a esta pérdida de tensión entre naturaleza y cultura, simultáneamente, las obras de arte parecen vivir en un "tiempo ideal", en un tiempo intemporal, pues se abstraen tanto de la historia anterior de la naturaleza como de la historia posterior de la cultura. Es que las obras de arte tienen una "pretensión de verdad", que como aclaramos más arriba no tiene que ver con la reproducción naturalista del mundo. La pretensión de verdad del arte no proviene de una ley externa a ella sino que es intrínseca a la propia obra, y se refiere a la autenticidad con la que la obra refleja la interioridad subjetiva del artista, o bien el espiritu del mundo al que representa, independientemente de la forma con que se presenta. En cada obra de arte, efectivamente, se condensa la voluntad y el sentir de un alma determinada, que puede ser individual o colectiva. Cada obra de arte contiene una cosmovisión, una experiencia de vida. Si este rasgo no se cumple, si no se manifiesta de modo fiel el espíritu de un individuo o de una época, entonces no se está frente a un fenómeno artístico:

"Por perfecto que sea el arte en sí mismo, en el momento en que pierde el sentido de la vida o que este sentido discurre en dirección opuesta, se convierte en artificiosidad" (Simmel, 2007: 45).

Un objeto puede reproducir la forma del mundo de un modo casi fotográfico, pero esto no garantiza su fidelidad al sentido del mundo representado. Una obra de arte es verdadera, entonces, si logra que cada uno de los elementos utilizados en su consecución esté puesto al servicio del significado general de lo representado. Una obra de arte es verdadera, en otras palabras, cuando logra manifestar con franqueza alguna de las múltiples formas en que la vida se despliega, en que la vida es posible. El arte verdadero es capaz, a la vez, de contener a un ser y de expresarlo, de totalizar su sentido y de mostrarlo en su complejidad. El arte es arte cuando es "más que arte", cuando es arte con espíritu.

\section{Análisis estilístico y cultural del arte}

En El conflicto de la cultura moderna Simmel afirma que existe una tragedia en la cultura moderna, un conflicto por el cual la vida espiritual sólo puede expresarse en formas culturales que, sin embargo, obstaculizan el devenir perpetuo de esa misma vida. Este conflicto, en realidad, es tan antiguo como la humanidad misma, pero se profundiza en la modernidad por la acumulación exacerbada de objetos culturales, los cuales sin embargo nunca logran contener a la vida de modo acabado. Esta tensión entre vida $\mathrm{y}$ forma, por supuesto, atraviesa al fenómeno artístico, en tanto el arte emerge como una de las formas en que se expresa la cultura.

"El movimiento creador de la vida ha producido ciertas formaciones en las cuales encuentra su exteriorización, las formas en que se realiza, formas que, por su parte, aceptan en sí las ondas de la vida venidera dándoles contenido $\mathrm{y}$ forma, lugar y orden: así ocurre con las [...] obras de arte [...] Pero estos productos de los procesos de la vida poseen la particularidad que, en el momento de su 
nacimiento, ya tienen un contenido propio y fijo que nada tiene que ver con el ritmo inquieto de la vida misma" (Simmel, 1923: 9).

Las formas en que se expresa el sentimiento artístico funcionan al modo de "casillas", es decir, funcionan encasillando el sentimiento artístico, imponiéndole una lógica propia y autónoma respecto a aquella que coordina al sentimiento puro. Si bien la autonomización de las formas es constitutiva del arte, este elemento suyo representa cierta detención de su también constitutiva dinámica vital. Las formas operan así oponiendo una resistencia al despliegue del espíritu artístico: una vez que un impulso adquirió una forma, es decir, una vez que adopta la forma de una obra de arte particular, aquel impulso ya no puede seguir expresando sus mutaciones inherentes. Si bien es cierto que puede hacerlo por medio de la producción de una nueva obra, de un nuevo objeto, de una nueva forma, nunca éstas lograrán abarcar la totalidad del impulso; éste siempre se escapará, siempre habrá un resto que permanezca inaprehensible. Las formas artísticas se separan así de la dinámica que las creó, se abstraen de ella resultando incluso opuestas a ella. Los objetos artísticos, en tanto dadores de forma al contenido de la vida, se alienan, se enajenan, se presentan como extrañas a dicha vida, en lugar de ser la auténtica expresión de ella.

Del mismo modo pueden resultar obstáculos a la vida que busca expresarse, tanto las tradiciones como los métodos o los modelos artísticos ya afianzados en la cultura. En efecto, tener que insertarse en una tradición artística, tener que hacer uso de un método artístico dado, o tener que reproducir artísticamente un modelo de manera ajustada, operan como barreras al despliegue de la subjetividad del artista. Un artista que no cumpla estos requisitos podrá aparecer como desviado, como ilegítimo, o incluso podrá no ser apreciado como artista. Sin embargo, postula Simmel, la verdadera obra ilegítima, por inauténtica, es aquella que se atiene a los cánones impuestos por la cultura en lugar de atenerse a los dictados de la propia interioridad. Así:

"En todo gran artista y en toda gran obra de arte hay algo más profundo, más amplio, algo que mana de fuentes más ocultas, que lo que el arte manifiesta en su sentido puramente artístico, pero que es por el arte aprehendido y llevado a la representación $\mathrm{y}$ perceptibilidad" (Simmel, 1923: 21).

Para el autor, la creación del artista puede definirse idealmente como la inmediatez entre una determinada conmoción espiritual y su continuación en una forma que la exprese. Para graficar esta concepción, Simmel recurre a la figura del grito como emanación automática frente al dolor. Los movimientos que el cuerpo del artista realiza para dar forma a su obra deberian ser, idealmente, casi automáticos, no mediados por ninguna racionalidad conciente, casi como reacciones instintivas frente al estímulo espiritual. Sólo de este modo, la obra de arte podría ser la expresión fiel, no alienada, de la vida interna que le dio su forma. En este sentido decíamos en el apartado anterior que el arte es más que arte, que el arte es más que una representación perceptible de una realidad: el arte debe ser otra forma de esa realidad misma. En el arte siempre hay algo más que lo que se expresa en su forma, algo del orden de los contenidos de la experiencia vital.

Por todo esto es que el sujeto se ve tanto atraído como expulsado frente al arte, el arte le agrada y le causa rechazo a un mismo tiempo, puesto que por un lado revela una fuerza viva, pero por otro la coarta, la presenta en su forma muerta. La obra de arte es un trozo de Yo, pero como todo trozo de humanidad causa repulsión, del mismo modo que un trozo apartado de un cuerpo, al perder conexión con el todo viviente, sólo puede ser un cadáver. El sujeto, entonces, se ve simultáneamente amalgamado con la obra de arte y alejado respecto de ella. Esta es la tragedia de la tensión entre forma y vida, o la tragedia de la cultura: el hombre necesita de ella para sentirse completo, para realizarse, pero 
nunca logra completarse ni realizarse del todo. Si bien el arte, como concepto, escapa a la tragedia porque contiene en sus formas a la vida, en los hechos puede suceder que no lo haga (Simmel, 1988b).

Pero si la obra de arte nunca alcanza su fin, siempre escurridizo, ¿cuándo puede decirse que ella está terminada? ¿Cuándo puede concebirse como objeto acabado? En Filosofía del dinero Simmel nos ofrece las siguientes pautas para responder estas preguntas:

"E1 proceso artístico culmina cuando ha desarrollado el objeto hasta su significación más peculiar. De hecho, el mero ideal artístico queda satisfecho con esto, puesto que, para él, la realización completa de la obra de arte, como tal, es un valor objetivo, completamente independiente de sus consecuencias para nuestro sentimiento subjetivo: el lema de l'art pour l'art [el arte por el arte] señala con exactitud la autosuficiencia de la tendencia artística pura" (Simmel, 1977: 561-562, aclaración entre corchetes propia).

El "ideal artístico", tal parece, no se equivale con lo que más arriba hemos dicho respecto del "impulso artístico". El ideal artístico es un valor objetivo, mientras que el impulso artístico es un valor subjetivo. Esto implica que una obra de arte, aún si no logra expresar la totalidad de la interioridad de un artista, o la totalidad del espíritu de una época -de hecho, como hemos visto, esto es imposible-, ella vale como objeto cultural, es decir, ella contribuye al acrecentamiento del acervo cultural colectivo. De este modo, cabe decir que el arte vale por sí mismo, y es, en cierto modo, autónomo respecto a los artistas mismos. El arte es entonces un fenómeno bifaz: una cara presenta un rasgo particular -subjetivo-, y la otra un rasgo general -objetivo-. Y estas dos caras son en realidad meras distinciones analíticas, pues en la práctica se encuentran intimamente superpuestas. La más profunda subjetividad es producto de la experiencia de dicho individuo en una existencia colectiva; del mismo modo, el valor objetivo de las obras no es sino la potencialidad de su reapropiación por parte de los individuos que entran en contacto con ellas (Simmel, 1986a).

Siguiendo esta misma línea, podemos decir con Simmel que el arte no es entonces solamente un producto humano sino también un hecho productor de humanidad. En otras palabras, el arte no es sólo un efecto de la vida, sino causa de ella en la misma medida. El arte, precisamente, va dando forma a la concepción humana del mundo: a su concepción de la naturaleza y de sí misma, de cada individuo y como grupo. La obra de arte no sólo es una representación $a$ posteriori de la experiencia anterior del mundo, sino que en ese representarlo lo produce como a priori de la experiencia posterior. La obra de arte, afirma el autor, se presenta a la conciencia humana como el "cuadro sensorial" de su experiencia del mundo (Simmel, 1977). O como afirma en El individuo y la libertad. Ensayos de critica de la cultura:
"Todo arte se nutre del suelo de las impresiones inmediatas de realidad, si bien se convierte en arte por vez primera alli donde crece más allá de este suelo; el arte presupone precisamente un proceso de reducción interno, inconciente, para persuadirnos de su verdad $y$ de su significatividad" (Simmel, 1986b: 224).

Vuelve a aparecer aquí la tensión entre alejamiento y acercamiento en la concepción del arte del autor, así como la tensión entre forma abstracta y contenido sustantivo. Si por un lado la obra de arte se nutre de la realidad, por otro lado la realidad se ve nutrida por ella. Si por un lado la obra de arte se autonomiza respecto del mundo, por otro lado el mundo se autonomiza respecto de ella. Ahora bien, la distancia entre obra de arte y experiencia vital no es siempre la misma, y justamente la gradación de esa distancia es la que rigen los distintos estilos artísticos. Los estilos en el arte son entonces consecuencia de los diversos niveles de acercamiento entre las formas y la vida. En los dos 
extremos se ubican el estilo naturalista y el fantástico, siendo el primero el más cercano y el segundo el más distante, pero en última instancia cada obra de arte singular implica una amplitud particular entre los dos polos. Simmel llega a afirmar, incluso, que frente a la "fría extranjeria" del mundo externo, la obra nos presenta la cálida familiaridad de una interioridad singular. Pero paralelamente, como ya hemos visto, la obra nos hace retroceder respecto de la inmediatez de la experiencia vivida, poniendo una especie de "velo" entre nosotros y ella.

En El arte y el estilo, Simmel postula que la relación entre arte y estilo es la siguiente: cuanta más profundidad exprese una obra de arte, menos relevante es su clasificación estilística, que entonces se reduce a una mera cuestión de forma. Cuando una obra de arte cautiva a quien la contempla, es porque ha logrado que el sujeto se sumerja en su interioridad. En este caso de intimidad entre obra y espectador, el hecho de que la obra pertenezca a un determinado estilo carece de sentido. Sólo cuando el espectador no logra aproximarse de manera directa a la obra, utilizará la mediación del estilo para aprehenderla. En este caso, sólo se alcanza a percibir de la obra de arte lo que ella presenta de típico y general:

"El estilo es siempre aquella manifestación formal, que -en la medida que sostiene o ayuda a sostener la impresión de la obra de arte- niega su naturaleza y su valor individuales, su significado singular. Gracias al estilo se somete la particularidad de una obra singular a una ley formal general que también es aplicable a otras obras de arte, se la despoja, por decirlo así, de su absoluta autonomía, ya que comparte con otras su naturaleza o una parte de su configuración y con ello hace referencia a una raíz común, que está más allá de la obra individual, en contraste con las obras que han surgido por entero de sí mismas, o sea de la unidad absoluta y misteriosa de su personalidad artística y de su genuina singularidad" (Simmel, 1994: 320).

Se vislumbra aquí una nueva particularidad de la diferencia de principio entre las bellas artes y las artes aplicadas. La esencia de las artes aplicadas es que sus objetos son muchos: su esencia es la cantidad, y no la cualidad, esencia de las bellas artes. La propagación y la utilidad son sus vectores principales. La interioridad del artista y su expresión a través de una obra de arte son completamente diferentes a la ejecución seriada de un modelo industrial. A pesar de la existencia de estilos artísticos, la obra de arte no es jamás la producción a partir de un patrón preestablecido. Mientras que un objeto industrial existe como medio para un fin que lo excede, un objeto estrictamente artístico existe como fin en sí mismo. Una obra de arte, en definitiva, y a diferencia de lo que sucede con un producto industrial, no es nunca una "cosa secundaria", sino un elemento primordial en el despliegue mismo de la vida (Guillet de Monthoux y Strati, 2002).

Vemos -y Simmel lo hace explícito en Rembrandt. Ensayo de filosofía del arte- que el fenómeno artístico es pasible de ser analizado de muy diversos modos. Pero un análisis de cada una de sus partes constituyentes nunca permitirá alcanzar una comprensión cabal del fenómeno total como tal. Un abordaje por partes o componentes no reconstituye el sentido de una obra de arte, como la mera suma de trozos de un cuerpo humano no equivale a un organismo viviente $y$ en pleno funcionamiento. Por esto es que no puede decirse que el efecto de una obra de arte sea igual a la suma de sus partes: éste es siempre un hecho unitario que se eleva por encima de sus manifestaciones fenoménicas singulares:

"Sólo el arte, cuyas
objetivaciones dejan a salvo las
más próximas referencias a la
inmediatez subjetiva de la vida
interior, parece lograr un reflejo
relativamente no deformado de
aquella unidad -no es una
reunión de lo separado, una
sintesis cuyas costuras jamás


se cerrarian, sino que el arte es un reflejo de la inseparabilidad originaria, que es pre-sintética y pre-analitica-" (Simmel, 1950: 30).

$\mathrm{El}$ arte como hecho unitario no es producto tampoco de una sintesis -por muy acabada que esta pueda ser- entre dichos elementos, sino que es la expresión de la unidad original de toda vida. Aquí Simmel refiere, notablemente, al fenómeno primordial de la inseparabilidad entre el cuerpo materno y el cuerpo de su cria. Todo análisis -en el sentido etimológico de separación de partes constituyentes: ana-lisis- que pueda realizarse, será siempre posterior al fenómeno artístico creado. Evidentemente, una vivencia originaria de aquel tipo, asi como su manifestación a través del arte, no pueden, por su naturaleza misma, ser abordados como hechos científicos, no pueden ser estudiados científicamente. El arte, si bien permite ser abordada desde matrices "filosófico-metafísicas", en última instancia sólo puede aprehenderse en su totalidad si es sentido, si es vivido. El arte existe más allá de su conceptualización, en la profundidad de los "conflictos históricos universales".

En efecto, no es posible fijar unívocamente la vivencia primaria del arte. Si bien puede teorizarse sobre ella hasta cierto punto, su vivencia permanece algo inaccesible a la teoría. Esto es lo que Simmel denomina la "efectividad" de la obra de arte, su carácter indisolublemente primario y unitario. Justamente, el arte configura la vivencia humana de tal modo que lo que podria aparecer como fenómeno dual -físico y psíquico a la vez, es decir, perceptible e interpretable- es en realidad un hecho total de la experiencia. El arte no es entonces la unidad de algún concepto que pudiese encontrarse detrás de ella, sino su inmediata "intuitividad". Frente a la obra de arte se tiene una impresión indivisa, que resulta en última instancia imposible de expresar en palabras, incluso en pensamientos.

"La obra de arte es siempre una objetivación del sujeto y por eso alcanza su puesto allende la realidad que siempre se adhiere al objeto en sí misma o al sujeto

en sí" (Simmel, 1950: 39).

Si el arte es la necesaria objetivación del sujeto en su devenir, es decir, es la formatización del contenido de una subjetividad, entonces el arte se ubica en un nivel vital incluso más profundo que el de la realidad del mundo práctico, que justamente se define por moverse en el nivel de los objetos -o de los sujetos tomados como objetos-. La obra de arte se nutre de cuantos elementos de dicha realidad práctica se quiera, pero su impulso originario proviene de un estrato vivencial, en cierto sentido, anterior. De hecho, el arte sólo es arte cuando ha modificado dichos elementos a partir de la conmoción espiritual que la impulsó. En este sentido, la obra de arte es como un puente entre la realidad interior y la realidad exterior. La obra de arte no nos reconduce de manera directa hacia la realidad del mundo práctico, sino de una manera muy indirecta y mediada por la subjetividad (Torterola, 2007).

La obra de arte, entonces, es la objetivación de la subjetividad del artista, pero no es sólo su espíritu lo que el artista pone en la obra de arte, sino también, por así decir, el espiritu del mundo representado. El alma de la obra de arte, entonces, es doble: surge del encuentro intimo entre el sujeto y el mundo. La extensión de la obra de arte en el espacio y en el tiempo, su materialidad colores, palabras, movimientos, sonidos, etcétera-, se unen dando lugar a la expresión de esa doble espiritualidad. Por supuesto, el "germen anímico" de dicha espiritualidad carece de forma propia, es informe, y sólo se formatiza al devenir obra de arte. Este germen anímico es aquella intuitividad mencionada, que es la verdadera esencia de toda auténtica obra de arte:

"El hecho de que cada instante de la vida es toda la vida -o más precisamente que la vida es total- es el que la expresión artística revela con pureza y univocidad" (Simmel, 1950: 7677).

Terminamos de comprender aquí la tensión entre fragmento y totalidad esbozada más 
arriba. Una obra de arte puede contener a la totalidad de la vida, porque cada fragmento de vida contiene ya a la vida entera. La obra de arte se nutre de la realidad, únicamente porque la realidad se nutre de la vida. Para terminar de delinear los tres conceptos centrales hasta aquí estudiados -"arte", "obra de arte" y "artista", podríamos decir entonces que si la obra de arte es sobre todo su forma -material, objetiva, estilística-, y el artista es el sujeto vivo -con su existencia psíquica, emocional, espiritual-, entonces el arte es la dialéctica entre ambas, entre forma y vida: es la vida contenida en formas, pero siempre rebasándolas.

\section{Conclusiones: la sociología y el arte}

Luego de rastrear los modos en que Simmel caracteriza al arte, y particularmente los modos en que el arte se entrelaza al resto de los fenómenos sociales, nos interesa ver de qué modo lo antedicho se combina para dar lugar a un modo particular de entender a la sociología. Si la sociología es la disciplina que se dedica al estudio de los fenómenos sociales, y ellos pueden ser caracterizados, mediante múltiples analogías, con el fenómeno artístico, entonces tenemos una primera explicación de por qué el análisis sociológico es un análisis estético. Por otro lado, si el arte mismo es una de las formas paradigmáticas en que se expresa la vida social, tanto en su faz colectiva como en su faz individual, entonces tenemos aquí una segunda justificación de dicha afirmación. La especificidad de la disciplina sociológica es el estudio de las formas, con independencia de los contenidos, de la vida social; las formas de vida social, en tanto estilizaciones de dicha vida en su eterno despliegue, son aprehensibles de manera estética; en tanto expresiones de la cultura humana, son aprehensibles de manera artística; y por ello, en definitiva, la captación de las culturas y los estilos de las formas de vida social deviene posible a través de la sociología como mirada artística y estetizante de las mismas (Davis, 1973).

Si bien la sociología tiene algo de científica, en tanto que busca cierta sistematización de los resultados de sus observaciones sobre el mundo, dicho afán es siempre parcial porque subsiste un resto de la observación que no puede sistematizarse. La observación del mundo social, en última instancia, se posa sobre la impresión, la intuición y la apreciación, producto de los impulsos originarios del espiritu humano, el cual emerge en la materialidad de ese mundo que se observa tanto como en el acto -y la necesidad misma- de observarlo (Morresi, 2003). Retomando algunas de las metáforas aportadas por el autor, la sociologia es entonces efectivamente, al igual que el arte, una forma de trazar un "puente", en este caso entre el mundo observado y el sujeto observante, pero también entre el mundo observado en el presente y la historia de ese mundo, y entre su estado real, presente y concreto y los anhelos de futuro de los sujetos que en él habitan. Al igual que el arte, la sociología es entonces también un "grito", un discurso expresivo y emotivo que externaliza, objetivándolo en palabras, el sentimiento que dicho mundo produce en los sujetos por medio de su vivencia de él, en toda su materialidad y en constante enfrentamiento con la vida psíquica de esos mismos sujetos.

La sociología es una mirada singular, y como toda mirada humana guarda en su seno algo de artística, por su conexión intima con la experiencia totalizante de la unidad estética originaria, así como con la apreciación de la heterogeneidad de sus manifestaciones. Por ello, como anunciamos en la introducción de este trabajo, si la sociología es un arte, es porque el mundo es una obra, a la cual el sociólogo-artista admira, y a la cual luego plasma en sus postulaciones, volviendo a intervenir en él, dándole una forma nueva. El discurso de la sociología sería entonces como una artesanía colectiva, representación a su vez de la estética del mundo social del cual habla. Sus temas, sus estilos, sus tradiciones y sus escuelas, así como las distintas tonalidades que adopta son elocuentes al respecto. En el interior de la comunidad que conforma, se juega y se compite; sus miembros son seducidos por el mundo al que observan con erotismo; sus escritos conforman, cuando son realizados con vocación 
estética, verdaderos paisajes de las formas de vida humanas (De La Fuente, 2007). Y este modo de concebir la tarea de la sociología nos parece sumamente valioso

\section{Bibliografia}

Castillo Castillo, José (1998). "El estilo de Simmel". Revista Española de Investigaciones Sociológicas, 84: 312-317.

Davis, Murray S. (1973). "Georg Simmel and the aesthetics of social reality". Social Forces, 51 (3): 320-329.

De La Fuente, Eduardo (2007). "On the promise of a sociological aesthetics: From Georg Simmel to Michel Maffesoli". Distinktion, 15: 93-112.

De La Fuente, Eduardo (2008). "The art of social forms and the social forms of art: the sociology-aesthetics nexus in Georg Simmel's thought". Sociological Theory, 26 (4): 344-362.

Fedorovsky, Johanna M. (2011). "La noción de arte en G. Simmel y H. G. Gadamer: una posible crítica a los planteos estéticos de W. Benjamin". VI Jornadas de Jóvenes Investigadores del Instituto Gino Germani, Buenos Aires, Argentina.

Frisby, David (1992). Sociological impressionism. A reassessment of Georg Simmel's social theory. Londres: Routledge.

Guillet de Monthoux, Pierre y Strati, Antonio (2002). "Modernity/art and marketing/aesthetics. A note on the social aesthetics of Georg Simmel". Consumption, Markets \& Culture, 5 (1): 1-11.

Morresi, Zulema (2003). "Georg Simmel: el arte de investigar". La Trama de la Comunicación, 8: 1-6.

Quiña, Guillermo M. (2013). "Simmel y Benjamin: aportes en clave romántica al análisis crítico de la cultura". Question, 38 (1): 1-12.

Rammstedt, Otthein (1991). "On Simmel's aesthetics. Argumentation in the Journal Jugend (1897-1906)". Theory, Culture \& Society, 8 (3): 125-144.
Simmel, Georg (1923). El conflicto de la cultura moderna. Córdoba: Universidad Nacional de Córdoba.

Simmel, Georg (1934). "La aventura". Cultura femenina y otros ensayos. Madrid: Revista de Occidente.

Simmel, Georg (1939a). "La lucha". Sociologia. Estudios sobre las formas de socialización. Buenos Aires: Espasa-Calpe.

Simmel, Georg (1939b). "El secreto y la sociedad secreta". Sociología. Estudios sobre las formas de socialización. Buenos Aires: Espasa-Calpe.

Simmel, Georg (1950). Rembrandt. Ensayo de filosofía del arte. Buenos Aires: Nova.

Simmel, Georg (1977). "El estilo de vida". Filosofía del dinero. Madrid: Instituto de Estudios Politicos.

Simmel, Georg (1986a). "De la esencia de la cultura". El individuo y la libertad. Ensayos de critica de la cultura. Barcelona: Península.

Simmel, Georg (1986b). "Estética sociológica". El individuo y la libertad. Ensayos de crítica de la cultura. Barcelona: Península.

Simmel, Georg (1988a) "La coquetería". Sobre la aventura. Ensayos filosóficos. Barcelona: Península.

Simmel, Georg (1988b). "Sobre filosofia de la cultura". Sobre la aventura. Ensayos filosóficos. Barcelona: Península.

Simmel, Georg (1994). "El problema del estilo". Revista Española de Investigaciones Sociológicas, 84: 319-326.

Simmel, Georg (2002). "La sociabilidad". Cuestiones fundamentales de sociología. Barcelona: Gedisa.

Simmel, Georg (2007). Roma, Florencia, Venecia. Barcelona: Gedisa.

Torterola, Emiliano (2007). "Cultura y civilización. Del romanticismo alemán a la sociología de Georg Simmel". Papeles de Trabajo, 2 (1): 1-17. 